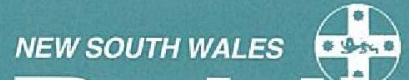 Public Health Bulletin
}

\section{THE HEALTH OF THE PEOPLE OF NSW REPORT OF THE CHIEF HEALTH OFFICER 1997}

Edited by Gerard Fitszimmons and Louisa Jorm,

Epidemiology and Surveillance Branch, Public Health Division, NSW Health Department

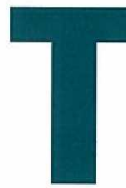

he second report of the NSW Chief Health Officer will be released in January 1998. Like the first, the report gives a concise overview of the health status of the NSW population. However, both content and layout have been considerably improved, according to recommendations from the evaluation of the first report and requirements for publishing via the World Wide Web. Where possible, trend data for the past 10 years are presented, and breakdowns by Area Health Service are given for key health indicators. Each page of the report stands alone and contains a graph, a table of figures and commentary text, making it suitable for viewing on-line. An interactive version is planned for release in mid-1998.

The report has four sections: Patterns of health and illness, Determinants of health, Health inequalities and Health priority areas. Some of its major findings are reproduced here.

\section{PATTERNS OF HEALTH AND ILLNESS}

\section{Demography}

In 1996, approximately half the NSW population was aged 35 years or over. Because birth rates are expected to remain stable and migration at or below current levels, the population will gradually age. In 1996 a little more than 21 per cent of the NSW population spoke a language other than English at home.

\section{Health of mothers and babies}

In 1995 almost 88,000 births were registered in NSW. Between 1986 and 1995 the crude birth rate fell from 15.4 to 14.2 per 1,000 population, and the median age of mothers giving birth increased from 28.3 years to 29.1 years. Deaths from sudden infant death syndrome (SIDS) in NSW have fallen by around two-thirds over the 10 years, from 205 in 1986 to 72 in 1995.

\section{Disability and self-assessed health}

In 1995 fair or poor health was reported with similar frequency by men (17.5 per cent) and women (17.3 per cent). Self-reported health declined with age. In 1993 more than one million NSW residents had a disability. The prevalence of disability increased with age, to 65 per cent among people aged 75 years and over. Almost 80 per cent of people with a disability had a handicap which limited their ability to perform tasks associated with daily living.

\section{Contents}

\section{Articles}

77 The Health of the People of NSW - Report of the Chief Health Officer 1997

81 Program budgeting and marginal analysis in NSW

84 Normal immunoglobulin (buman): indications and safety

85 Changes to the NSW Public Health Act 1991 -

Reporting of birth defects

86 Infectious Diseases

\section{Correspondence}

Please address all correspondence and potential contributions to:

\section{The Editor,}

NSW Public Health Bulletin, Public Health Division, NSW Health Department Locked Bag No 961, North Sydney NSW 2059 Telepbone: (02) 93919191 Facsimile: (02) 93919232 


\section{FIGURE 1}

POTENTIAL YEARS OF LIFE LOST (PYLL) BEFORE THE AGE OF 75, BY CATEGORY OF CAUSE OF DEATH, NSW 1994

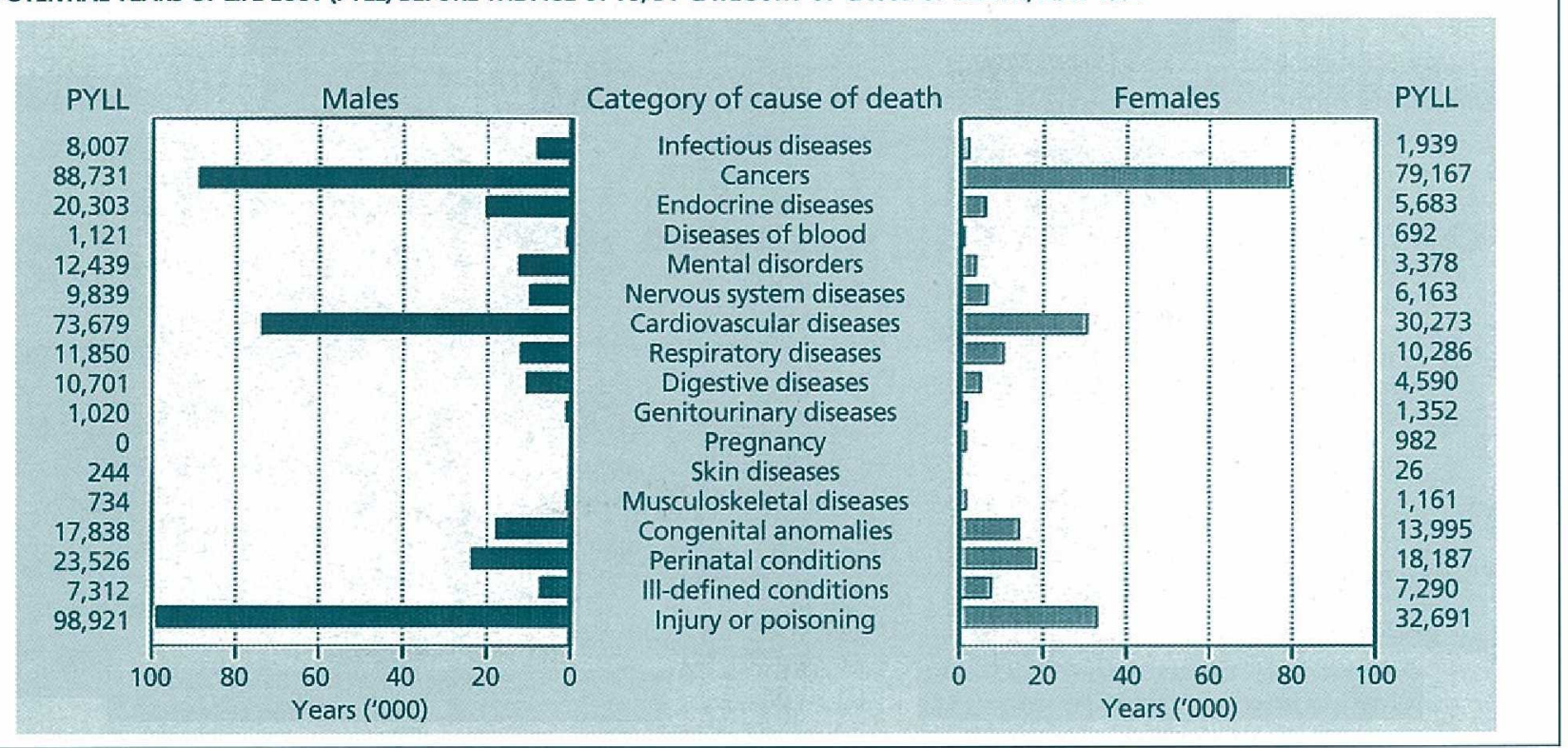

Note: Cause-deleted potential years of life lost were calculated from the 1994 NSW current life table. Cause of death was classified according to ICD-9 chapter headings using the codes 000 to 799, or using the Injury/poisoning external cause codes E800-869, E880-929, E950-999.

Source: ABS mortality data (HOIST), Epidemiology and Surveillance Branch, NSW Health Department.

\section{Health of the people of NSW}

\section{$\checkmark$ Continued from page 77}

\section{Hllness}

In 1995 the recent health conditions most commonly reported by NSW residents were headache, arthritis, high blood pressure, asthma and common cold, while the longterm health conditions most commonly reported were vision problems, arthritis, hay fever, asthma, high blood pressure, sinusitis and deafness. In 1995-96, respiratory diseases, diseases of the gastro-intestinal system and cardiovascular diseases were the most common causes of hospitalisation in those aged 0-14 years, 14-65 years and 65+ years respectively (excluding pregnancy-related admissions).

\section{Life expectancy}

Between 1985 and 1994 life expectancy at birth in NSW increased steadily, from 72.2 to 75.1 years for males and from 78.8 to 80.9 years for females. In 1994 the expected age at death for those having reached the age of 65 years was 84.5 years for women and 81.0 years for men.

\section{Deaths}

In 1994 most deaths among children aged 0-14 years were due to perinatal conditions and congenital anomalies. The most important causes of death among people aged 15-64 years were cancer, circulatory diseases and injury and poisoning. Circulatory diseases were the most important causes of death in people aged 65 years and over. Potential years of life lost (PYLL) before age 75 is a measure of premature mortality. In 1994 breast cancer was the single largest cause of PYLL in females, followed by ischaemic heart disease, motor vehicle traffic accidents, lung cancer and suicide. Ischaemic heart disease was the single largest cause of PYLL in males, followed by suicide, motor vehicle traffic accidents, lung cancer and colorectal cancer.

\section{DETERMINANTS OF HEALTH}

\section{Health-related behaviours}

In 1996 only half of NSW adults expended enough energy on leisure-time activity for health benefit. Men ( 59 per cent) were more likely to report adequate levels of activity than women (42 per cent). In 1994 women were more likely to report using sunscreen and wearing sunglasses, while men were more likely to wear protective clothing or hats. In 1995 almost half of NSW men (47 per cent), and less than onethird of women ( 28 per cent) reported being overweight or obese. Men reported eating greater quantities of fatty foods. Smoking levels in NSW have declined by around one-third since 1977. In 1995, 27 per cent of men and 20 per cent of women reported current smoking. In the same year 10 per cent of men and 6 per cent of women reported drinking alcohol at medium- or high-risk levels.

\section{Health and the environment}

Concentrations of lead in ambient air in Sydney have been steadily declining in recent years. The number of days on which desired goals for atmospheric fine particles, nitrogen dioxide and ozone have been exceeded have also declined. Drinking water from Sydney and Hunter Water has complied with guidelines for coliforms, aluminium, lead and pesticides in recent years. Rural water supplies as a whole have also generally complied with guideline levels, but in 


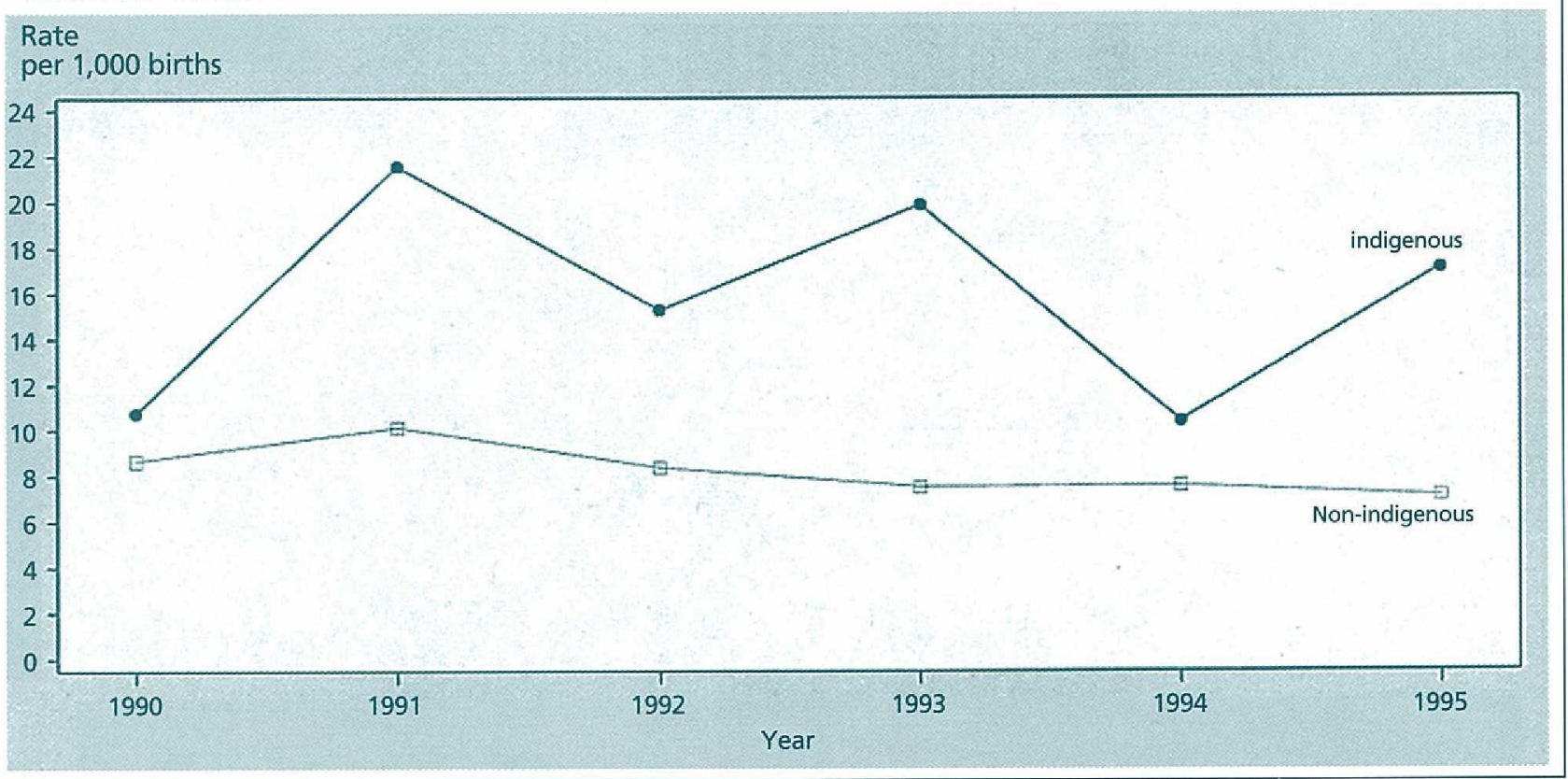

Notes: Deaths within 28 days of birth were classified as perinatal deaths. Infants with birth-weight of 600 grams or more or, if birth-weight was unknown, of at least 22 weeks gestation, were included. Births for which mother's indigenous status was missing were classified as non-indigenous. Sources: NSW Midwives Data Collection and ABS perinatal mortality data (HOIST), Epidemiology and Surveillance Branch, NSW Health Department.

three instances in the period 1994-1997, levels of pesticides exceeding guideline values were detected.

\section{HEALTH INEQUALITIES}

\section{Health of Aboriginal and Torres Strait Islander peoples}

Aborigines and Torres Strait Islanders comprised 1.3 per cent of the NSW population at the 1991 census and 2.3 per cent of the population at the 1996 census. Much of the increase was due to an increasing level of self-identification among indigenous people. In 1996 only 13 per cent of the indigenous population was aged 45 years or over (compared with 34 per cent of the total population). In the period 19901994 the perinatal mortality rate and the prematurity rate for babies of indigenous mothers were much higher than for other NSW babies. Less than half of deaths among indigenous people in NSW are recorded as such, making death data unreliable. Even though indigenous status is also under-reported in NSW hospital data, reported hospitalisation rates for indigenous people for cardiovascular diseases, diabetes mellitus, respiratory diseases, lung cancer and injury and poisoning are consistently around double those for non-indigenous people.

\section{Country-of-birth differentials}

In the period 1989-1993 NSW residents born in most overseas countries experienced lower death rates than for all NSW. Selection processes at least partly explain the low death rates among immigrants. People born in Malta,
Lebanon, India (men), Italy (women) and the former Yugoslavia (women) have a higher death rate from diabetes than for NSW as a whole. Women born in Fiji and Vietnam experienced significantly higher incidence rates for cervical cancer than for all NSW women, while women born in the United Kingdom had significantly higher death rates from breast cancer.

\section{Socioeconomic status and health}

In the period 1990-1994 the NSW local government areas with the lowest socioeconomic status (SES) had the highest rates of premature death and hospitalisation. The association between low SES and premature death was observed for a range of causes, including cardiovascular diseases, injury and poisoning, respiratory diseases, lung cancer and cervical cancer. Premature deaths from breast cancer, prostate cancer and colorectal cancer showed virtually no correlation with SES.

\section{HEALTH PRIORITY AREAS}

Cardiovascular diseases

Deaths due to coronary heart disease (CHD) and stroke have been declining in NSW since the 1960s. Nevertheless, CHD caused 10,900 deaths (24 per cent of all deaths) in NSW in 1994 and stroke caused 4,820 deaths (11 per cent of all deaths). The declines have been accompanied by increases in hospitalisations for these conditions: 


\section{FIGURE 3}

NOTIFICATIONS AND HOSPITAL SEPARATIONS FOR HAEMOPHILUS INFLUENZAE INFECTIONS, CHILDREN AGED 0-4 YEARS, NSW 1992 TO 1996 (NOTIFICATIONS), NSW 1990/91 TO 1995/96 (SEPARATIONS)

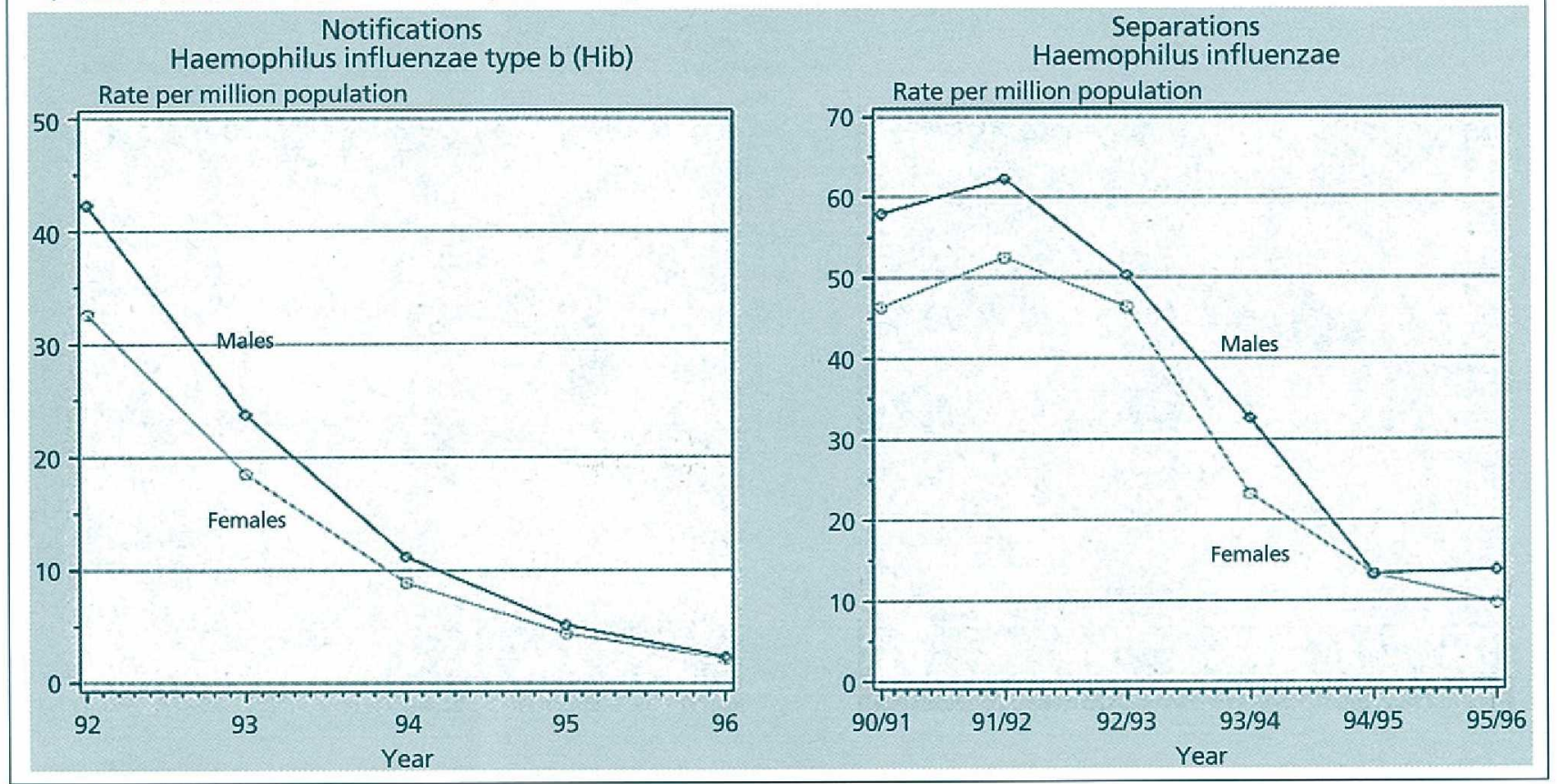

Note: Data were generated on October 15, 1997, and included children aged 0-4 years whose sex was unknown. Notification rates were age-adjusted using the Australian population as at June 30, 1991. Haemophilus influenzae separations were classified according to the ICD-9 codes 320.0 or 464.3 . Haemophilus Australian population as at June 30, 1991. Haemophilus influenzae separations were classified according to the ICD-9 codes not specified as an ICD-9 code. Hospital separation rates were age-adjusted using the Australian population as at December 31 , 1991 . Hospital separations in 1995-96 do not include NSW residents treated in Victoria, South Australia, Western Australia or Queensland.

Sources: NSW Health Department Infectious Diseases Surveillance System (IDSS) and Inpatient Statistics Collection (ISC) and ABS population estimates (HOIST), Epidemiology and Surveillance Branch, NSW Health Department.

\section{Health of the people of NSW}

\section{Continued from page 79}

hospitalisations for CHD (mainly for non-infarct diagnoses) have increased by 44 per cent in the past seven years, while hospitalisation for stroke have increased by 12 per cent.

\section{Diabetes mellitus}

In 1994,5 per cent of NSW adults reported being told by a doctor or nurse that they had high blood sugar or diabetes. Prevalence increased with age, to around 10 per cent for people aged 65 years or over. Deaths recorded as due to diabetes have been relatively stable in NSW in recent years, but diabetes is under-reported as a direct cause of death, and may be a contributory risk factor in many deaths ascribed to cardiovascular diseases.

\section{Asthma}

In 1994, 14 per cent of NSW adults reported ever having being diagnosed with asthma. Asthma prevalence was highest among adults aged $18-24$ years. In the same year 9 per cent of NSW adults reported current asthma. The death rate from asthma in NSW has been declining gradually since 1989 . There were 309 deaths from asthma in 1994.

\section{Cancer}

In 1994 cancer caused 11,502 deaths among NSW residents. Breast cancer was the most common malignant cancer, and the leading cause of cancer death in women. New cases of breast cancer have increased gradually in recent years (partly owing to increased screening and early detection) but death rates have remained stable. Lung cancer was the most common cause of cancer death in males and the second most common in females. Male death rates from lung cancer have declined in recent years, but female death rates continue to rise. Prostate cancer was the most common malignant cancer and the second most common cause of cancer death in men. The reported rate for new cases of prostate cancer has risen rapidly in recent years.

\section{Injury and poisoning}

In 1994 injury and poisoning caused 2,930 deaths among NSW residents. The major causes of injury death were suicide, road injury, falls, unintentional poisoning, homicide and unintentional drowning. The main causes of injury hospitalisation in 1995-96 were falls, road injury, sports injury and unintentional cutting and piercing injuries. In the same year $12,810 \mathrm{NSW}$ children had a confirmed case of abuse or neglect reported to the Department of Community Services. 


\section{Mental health}

Around 18 per cent of NSW children and adolescents meet criteria for mental health problems at some time during a six-month period. Delinquency, thought disorders, attention problems and social problems are the most common mental health problems among children. Nearly 30 per cent of NSW adults may have at least one mental health disorder at some time during a 12-month period. The most common mental disorders in adults are major depressive episode, simple phobia, social phobia and alcohol dependence. In 1994, 797 deaths in NSW were caused by suicide or self-inflicted injury. Most of these deaths were in males. Death rates from suicide among young men aged 15-24 years have risen steadily over recent years.

\section{Infectious diseases}

Rates of Haemophilus influenzae type $\mathrm{b}$ (Hib) disease have declined substantially in NSW since the introduction of an effective vaccine in 1993. NSW has been in the grip of an extended outbreak of pertussis (whooping cough) since 1993. In late 1996 and early 1997 six NSW infants died of pertussis. Only 59.3 per cent of NSW children aged three months to six years were fully immunised in 1995. AIDS cases and deaths declined sharply in NSW in 1996; 338 new cases of HIV infection and 259 new cases of AIDS were reported in that year. Hepatitis $\mathrm{C}$ is the most commonly reported infectious disease in NSW, with 8,547 cases reported in 1996. The incidence of food poisoning in NSW appears to be increasing, with 1,248 reported cases of salmonella infection in 1996. Arboviral illness reports rose sharply in 1996 , with 1,268 cases reported compared with 551 the previous year.

\section{Dental health}

In 1996 about two-thirds of NSW kindergarten children and 57 per cent of children in grade 6 had experienced no tooth decay. On average, the children had one decayed, missing or filled tooth. Hospitalisations for removal or restoration of teeth rose in all age groups over the period 1989-90 to 1995-96.

Contributors to the report (in alphabetical order) were: Jody Aiken, Bruce Armstrong, Rona Baruch, Adrian Bauman, Bill Bellew, Lucy Burns, Jennifer Chipps, Tim Churches, Glenn Close, Stephen Corbett, Christine Cowie, Kate Cunningham, Gerard Fitzsimmons, Roberto Forero, Shing Chung Fung, Devon Indig, Louisa Jorm, Ed Kraa, Margaret MacDonald, Edwina Macoun, Jeremy McAnulty, Rob Menzies, Helen Moore, Geoff Morgan, David Muscatello, Ru Nguyen, Hanna Noworytko, Michele Puech, Deborah Sinclair, Gavin Stewart, Beth Stickney, Lee Taylor, Pat Ward, Rob Weidenhofer, Kim White, Maxine Whitlock and Margaret Williamson.

Copies of the report will be available from the Better Health Centre, 162 Blues Point Road, North Sydney NSW 2060, Australia. Phone: (02) 99541193 Facsimile: (02) 99555196 or from the NSW Health Department Web site at http://www.health.nsw.gov.au/publichealth/chorep/chorep.html

\section{Program BUDGeting AND MARGINAL ANALYSIS IN NSW}

Marion Haas, Gavin Mooney, Rosalie Viney and Lyn Cooper Centre for Health Economics Research and Evaluation, University of Sydney

n a previous issue of the NSW Public Health Bulletin, we reported the establishment of pilot projects in the use of program budgeting and marginal analysis (PBMA) to assist resource allocation and priority setting in NSW Area health services $^{1}$. This paper reports the results of these pilot projects.

The concept of measuring performance in terms of health outcomes and health improvement is widely understood and accepted in the health system. The challenge now is to use the concept of health improvement in practical planning of programs and services. This requires a focus on the process of planning and, in particular, priority setting.

In the past much of the emphasis in planning has been on identifying goals and targets and determining what the vision of the future is. While this is important, it tends to leave a gap between where we are now and achieving this vision. Service planning should be about judging where the service is, what the options are for change, what are the best options for change in terms of costs and benefits, and implementing change. One of the biggest challenges in this process is to link this with decisions about resource allocation and, in turn, to alter the balance of resources to achieve the optimal mix of services. It is resource allocation which drives our ability to deliver services, and changes in the delivery of services will only follow funding decisions. What economics contributes to planning is a focus on the role of resource allocation.

\section{OVERVIEW OF PROGRAM BUDGETING AND MARGINAL ANALYSIS}

Program budgeting and marginal analysis involves using principles of economics to assist the planning of services and the setting of priorities in resource allocation. It provides a framework for making decisions about how to shift resources and realign services to achieve health improvement and other potential benefits, while ensuring equitable access. It makes explicit the decisions about which services should be expanded and which contracted on the basis of what the effect of the altered pattern of services is on expected outcomes.

There are two stages. The first stage is the development of program budgets. These provide an information framework to allow the examination of the relationship between resource use, activities, outputs and objectives. A key feature of this framework is that programs are output and objective orientated rather than being focused on inputs and activities. For service planning, program budgeting is intended to answer the question "where are we now?".

Marginal analysis answers the question "what should we change?" In practice, the process involves developing and prioritising incremental and decremental "wish lists", i.e. activities which would be expanded if additional resources were available, and those which would be contracted if a budget cut were imposed. 